\title{
Use of a Silsesquioxane Organically Modified with 4-amino-5-(4-pyridyl)-4H-1,2,4-triazole-3-thiol (APTT) for Adsorption of Metal Ions
}

\author{
Layciane Aparecida Soares ${ }^{1}$, Tayla Fernanda Serantoni da Silveira ${ }^{1}$, Daniela Rodrigues Silvestrini ${ }^{1}$, Urquisa de \\ Oliveira Bicalho ${ }^{1} \&$ Devaney Ribeiro do Carmo ${ }^{1}$ \\ ${ }^{1}$ Departamento de Física e Química, Universidade Estadual Paulista, Ilha Solteira, Brazil \\ Correspondence: Devaney Ribeiro do Carmo, Departamento de Física e Química, Universidade Estadual \\ Paulista-UNESP, Av. Brasil Centro 56, Ilha Solteira, Brazil. Tel: 55-18-3742-1029. E-mail: \\ docarmo@dfq.feis.unesp.br
}

Received: December 17, 2012 Accepted: January 12, 2013 Online Published: January 21, 2013

doi:10.5539/ijc.v5n1p39

URL: http://dx.doi.org/10.5539/ijc.v5n1p39

\begin{abstract}
This paper describes the preparation of a nanostructured silsesquioxane, the cloropropilsilsesquioxano (S) that was organofunctionalised with the 4-amino-5-4(pyridyl)-4H-1,2,4-triazole-3-thiol (APTT), the material obtained of the functionalization was described as SA. The material SA was characterized by spectroscopy in the region of infrared (FTIR). After proper characterization, were carried studies on adsorption of metallic ions such as $\mathrm{Cu}^{2+}, \mathrm{Ni}^{2+}$ and $\mathrm{Cd}^{2+}$ in the active sites of SA. Different methods were studied in the adsorption of metal ions above: aqueous, ethanol $42 \%$ and ethanol $99 \%$, determining the adsorption equilibrium time, which for both means and metals the maximum time averaged 35 minutes. After determining the adsorption equilibrium time of metal ions in each system, we determined the specific sorption capacity $\left(N f^{\max }\right)$ through adsorption isotherms. The results suggest that the sorption of metal ions on DPPIPS occurs mainly by surface complexation and a Langmuir model allowed describing the sorption of the metal ions on SA. The excellent adsorptive capacity made possible the development of a method for determination of metal ions at trace level in real samples such as waste water, ethanol fuel and alcoholics beverages.
\end{abstract}

Keywords: silsesquioxane, functionalization, 4-amino-5-4(pyridyl)-4H-1,2,4-triazole-3-thiol, adsorption

\section{Introduction}

Silsesquioxanes are nanostructured compounds with an empirical formula $\left(\mathrm{RSiO}_{1.5}\right) \mathrm{n}$, where $\mathrm{R}$ is a hydrogen atom or an organic group (Cordes et al., 2010; Gnanasekaran et al., 2009; Baney et al., 1995; Kuo \& Chang, 2011; Xu et al., 2011; Tanaka \& Chujo, 2012; Hu \& Shea, 2011) and $n=4,6,8,10(n \geq 4)$ (Cordes et al., 2010) . Silsesquioxanes have a large number of applications, such as catalysts (Gnanasekaran et al., 2009; Kuo, \& Chang, 2011; Li et al., 2001; Provatas et al., 1998; Laine \& Roll, 2011), liquid crystals (Gnanasekaran et al., 2009; Cordes et al., 2010), biosensors (Cordes et al., 2010; Kuo \& Chang, 2011; Xu et al., 2011) and silica interface (Handke \& Kowalewska, 2011) and dendrimer precursors (Do Carmo et al., 2007). It is very interesting to know that their properties increase when these structures are functionalized with organic groups forming hybrid materials (Gnanasekaran et al., 2009; Xu et al., 2011).

Hybrid materials have been paid on considerable attention due to their organic and inorganic moieties working together to give the hybrid different properties from those displayed in their precursors (Yin et al., 2011b). Functionalized silsesquioxanes can improve some of their properties without affecting their characteristics, for example mechanical and thermal properties (Gnanasekaran et al., 2009; Kuo \& Chang, 2011; Xu et al., 2011) and also their oxidation resistance (Gnanasekaran et al., 2009). Currently, there is great interest in the formation of hybrid materials by incorporating of organic groups into structures of silsesquioxanes. Additionally, it can increase their adsorptive capacity of metal ions in solution (Paim, 2007). Metal coordination with silsesquioxane is common when use incompletely condensed silsesquioxanes such as trisilanol and Polyhedral Oligomeric Silsesquioxane (POSS). These complexes are capable of mimicking the main characteristics of the inorganofuctionalized silica with different metals (Dijkstra et al., 2002; Do Carmo et al., 2007; Duchateau et al., 2003; Feher \& Budzichowski, 1995; Lorenz et al., 2000). The adsorptive properties of nanomaterials 
silsesquioxanes based can be attributed mainly to the presence of peripheral organic groups, which contained $\mathrm{O}$, $\mathrm{S}$ and $\mathrm{N}$ in the functionalized silsesquioxane (Yin et al., 2011a, 2011b; Cai et al., 2011). In this context the main objective of this work was to organofunctionalize octa(3-chloropropyl)octasilsesquioxane (SS) with 4-amino-5-(4-pyridyl)-4H-1,2,4-triazole-3-thiol, also known as APTT groups (Figure 1b) in order to evaluate the adsorption capacity of metal ions $\left(\mathrm{Cu}^{2+}, \mathrm{Ni}^{2+}, \mathrm{Cd}^{2+}\right)$ in different media, such as aqueous, ethanol $(42 \%$ and $99 \%)$. APTT is a power ligand for organofunctionalization and sorption of metals. The presence of $\mathrm{N}$ and $\mathrm{S}$ sites can bind of different transition metals (Chu et al., 2007).

\section{Experimental}

\subsection{Reagents}

All reagents and solvents were of analytical grade (Alpha Aesar, Merck or Aldrich) and were used as purchased. Deionized water was produced with Milli-Q Gradient system from Millipore. The solutions of sodium nitrite were prepared immediately before use.

\subsection{Techniques}

Fourier transform infrared spectra were recorded on a Nicolet 5DXB FTIR 300 spectrometer. Approximately 600 $\mathrm{mg}$ of $\mathrm{KBr}$ was grounded in a mortar with a pestle, and sufficient solid sample was grounded with $\mathrm{KBr}$ to make a $1 \mathrm{wt} \%$ mixture to produce $\mathrm{KBr}$ pellets. After the sample was loaded, the sample chamber was purged with nitrogen for at least $10 \mathrm{~min}$. prior the data collection. A minimum of 32 scans was collected for each sample at a resolution of $4 \mathrm{~cm}^{-1}$.

\subsection{Synthesis}

\subsubsection{Synthesis of Octa-(3-chloropropyl)silsesquioxane (SS)}

For the synthesis of octa-(3-chloropropyl)silsesquioxane (SS) a procedure described in the literature was followed (Chojnowski et al., 2006). $800 \mathrm{~mL}$ of methanol, $27.0 \mathrm{~mL}$ of hydrochloric acid $(\mathrm{HCl})$ and $43.0 \mathrm{~mL}$ of 3-chloropropyliltriethoxysilane were added into a $1000 \mathrm{~mL}$ round bottom flask. The reaction was stirred at room temperature for 5 weeks. The solid phase was separated by filtration in a sintered plate funnel, yielded a white solid which was then oven dried at $120^{\circ} \mathrm{C}$ for 4 hours (Figure 1a).

\subsubsection{Functionalization of Octa-(3-chloropropyl)silsesquioxane with APTT (SA)}

The functionalization of octa-(3-chloropropyl)silsesquioxane (SS) (Figure 1b) was performed $500 \mathrm{~mL}$ 3-neck flask containing $9.70 \times 10^{-3} \mathrm{~mol}$ of SS, previously dried at $100{ }^{\circ} \mathrm{C}$ for 2 hours, $8.70 \times 10^{-2} \mathrm{~mol}$ of APTT and approximately $200 \mathrm{~mL}$ of dimethylformamide (DMF). The mixture was refluxed at $150{ }^{\circ} \mathrm{C}$ with constant stirring for 96 hours. Then the solid phase was separated in a sintered funnel and washed in a Soxhlet extractor with DMF for 48 hours. The material obtained was oven vacuum dried at $100{ }^{\circ} \mathrm{C}$ for 4 hours (Figure 1b). 


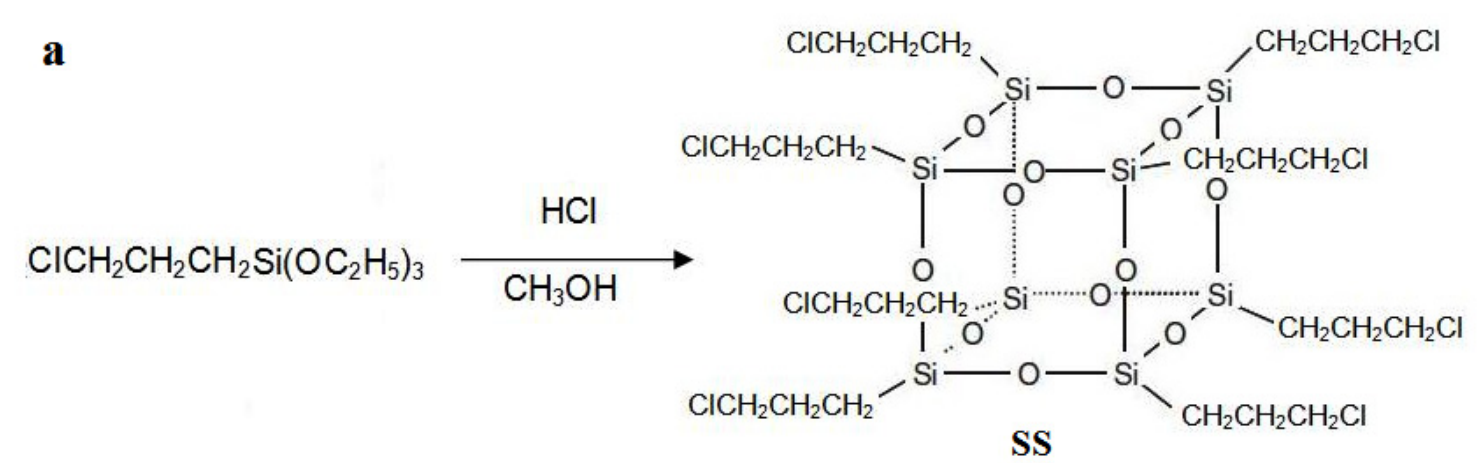

\section{b}<smiles>ClCCC[Si]12O[Si]3(CCCl)O[Si]4(CCCl)O[Si](CCCCl)(O1)O[Si]1(CCCCl)O[Si](CCCCl)(O4)O[Si](CCCCl)(O3)O[Si](CCCCl)(O2)O1</smiles><smiles>[R]CCC[Si]12O[Si]3(CCC[R])O[Si]4(CCC[R])O[Si](CCC[R])(O1)O[Si]1(CCC[R])O[Si](CCC[R])(O2)O[Si](CCC[R])(O3)O[Si](CCC[R])(O4)O1</smiles><smiles></smiles>

APTT

Figure 1. (a) Preparation of octa-(3-chloropropyl)silsesquioxane [19-adapted] and (b) organofunctionalization of octa-(3-chloropropyl)silsesquioxane (SS) with the modifying agent APTT

\subsection{Isotherms of Adsorption}

For studies of the adsorptive capacity of organofunctionalized material for metal ions $\left(\mathrm{Cu}^{2+}, \mathrm{Ni}^{2+}, \mathrm{Cd}^{2+}\right)$ in different media (aqueous, $42 \%$ ethanol and $99 \%$ ethanol) it was employed the batch technique. For each isotherm of adsorption, samples containing $50 \mathrm{mg}$ of SA in $50 \mathrm{~mL}$ solvent with variable concentrations of metal chloride $\left(0.25 \times 10^{-3}\right.$ to $\left.3.0 \times 10^{-3} \mathrm{~mol} \mathrm{~L}^{-1}\right)$ was mechanically shaken for average 35 minutes, at a constant temperature of 25 $\pm 1{ }^{\circ} \mathrm{C}$. After shaking, the solid phase was separated and an aliquot of $10 \mathrm{~mL}$ of solution containing the metal ions was titrated with EDTA solution $1.0 \times 10^{-3} \mathrm{~mol} \mathrm{~L}-1$, using murexide as indicator. The quantity of adsorbed metal, $\mathrm{Nf}$, in each flask was determined by the equation $\mathrm{Nf}=(\mathrm{Na}-\mathrm{Ns}) / \mathrm{m}$, where $\mathrm{m}$ is the mass $(\mathrm{g})$ of adsorbent and $\mathrm{Na}$ and Ns are the initial and the equilibrium amount of the number of moles of the metal in the solution phase, respectively.

\section{Results and Discussion}

Figure 2a refers to the spectrum of the APTT bond, showing characteristic bands of this ligand, which are the bands from 500 to $1600 \mathrm{~cm}^{-1}$, referring to the vibrations of the APTT ring. Similar to the bands at $\sim 1310,1415$ and $1550 \mathrm{~cm}^{-1}$ that correspond to the axial deformation C-N $\left(v_{\mathrm{C}-\mathrm{N}}\right)$, the axial deformation $\mathrm{C}-\mathrm{N}\left(\mathrm{v}_{\mathrm{C}-\mathrm{N}}\right)$ of the cycle, and angular deformation of N-H $\left(\delta_{\mathrm{N}-\mathrm{H}}\right)$ of the APTT ring, respectively. And in regions near to $1620 \mathrm{~cm}^{-1}$ there was a band attributed to the axial stretching $\mathrm{C}=\mathrm{N}\left(v_{\mathrm{C}=\mathrm{N}}\right)$. The band at $\sim 2790 \mathrm{~cm}^{-1}$ corresponds to the vibration of the S-H bond $\left(v_{\mathrm{S}-\mathrm{H}}\right)$, and the intense bandwidth is attributed to the $\mathrm{O}-\mathrm{H}$ deformation of the molecules $\mathrm{H}_{2} \mathrm{O}\left(v_{\mathrm{O}-\mathrm{H}}\right)$. Other absorption bands were observed, an intense broad band between 2300 and $2600 \mathrm{~cm}^{-1}$ which can be 
attributed to the axial deformation of $\mathrm{C}-\mathrm{H}\left(v_{\mathrm{C}-\mathrm{H}}\right)$ of the ring and two other bands at $\sim 3160$ and $\sim 3270 \mathrm{~cm}^{-1}$ referring to the axial deformation $\mathrm{N}-\mathrm{H}\left(\mathrm{v}_{\mathrm{N}-\mathrm{H}}\right)$ (Silverstein \& Welbster, 1996).

Figure $2 \mathrm{~b}$ illustrates the vibrational spectrum of the functionalized material (SA), showing bands that are characteristic of the precursor materials $\mathrm{S}$ and APTT, such as the bands at $\sim 1120 \mathrm{~cm}^{-1}$ related to asymmetrical stretching $\mathrm{Si}-\mathrm{O}-\mathrm{Si}\left(\mathrm{v}_{\mathrm{Si}-\mathrm{O}-\mathrm{Si}}\right)$ that correspond to that found for a cage-shaped structure of silsesquioxane, confirming that the cubic structure is maintained. The bands at 2900 and $2950 \mathrm{~cm}^{-1}$ attributed to the C-H bond vibration $\left(v_{\mathrm{C}-\mathrm{H}}\right)$ and the $\mathrm{Si}-\mathrm{H}$ vibration $\left(v_{\mathrm{Si}-\mathrm{C}}\right)$, respectively, and band width can be attributed to the $\mathrm{O}-\mathrm{H}$ deformation of molecules $\mathrm{H}_{2} \mathrm{O}\left(v_{\mathrm{O}-\mathrm{H}}\right)$. The bands between 1350 and $1650 \mathrm{~cm}^{-1}$ were attributed to the vibrations and deformations of the APTT ring (Silverstein \& Welbster, 1996). An absence of the band at $590 \mathrm{~cm}^{-1}$ related to the $\mathrm{C}-\mathrm{Cl}$ vibrations was also observed, therefore confirming the complete organofunctionalization of $\mathrm{S}$ with APTT.

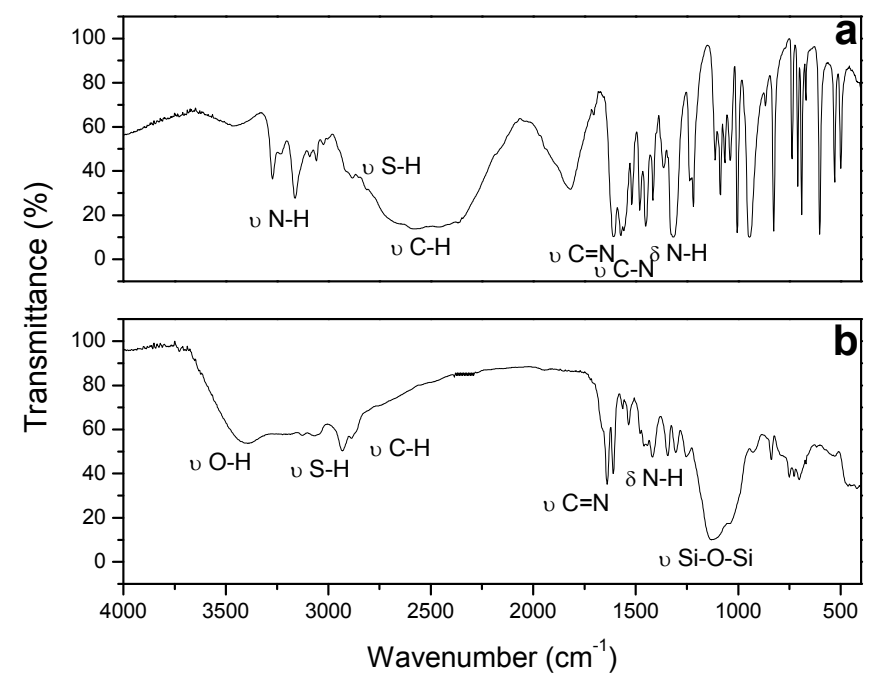

Figure 2. (a) Spectrum in the infrared region of APTT and (b) spectrum in the infrared region of SA

To evaluate the adsorption capacity of metal ions in different media (aqueous, ethanol $42 \%$ and ethanol $99 \%$ ), adsorption isotherms were obtained by plotting $N_{f}$ against $C$, where $C$ is the equilibrium concentration of the solute in solution phase. Figures 3, 4 and 5 illustrate the adsorption isotherms for copper, cadmium and nickel ions from different solvents onto SA surface. 


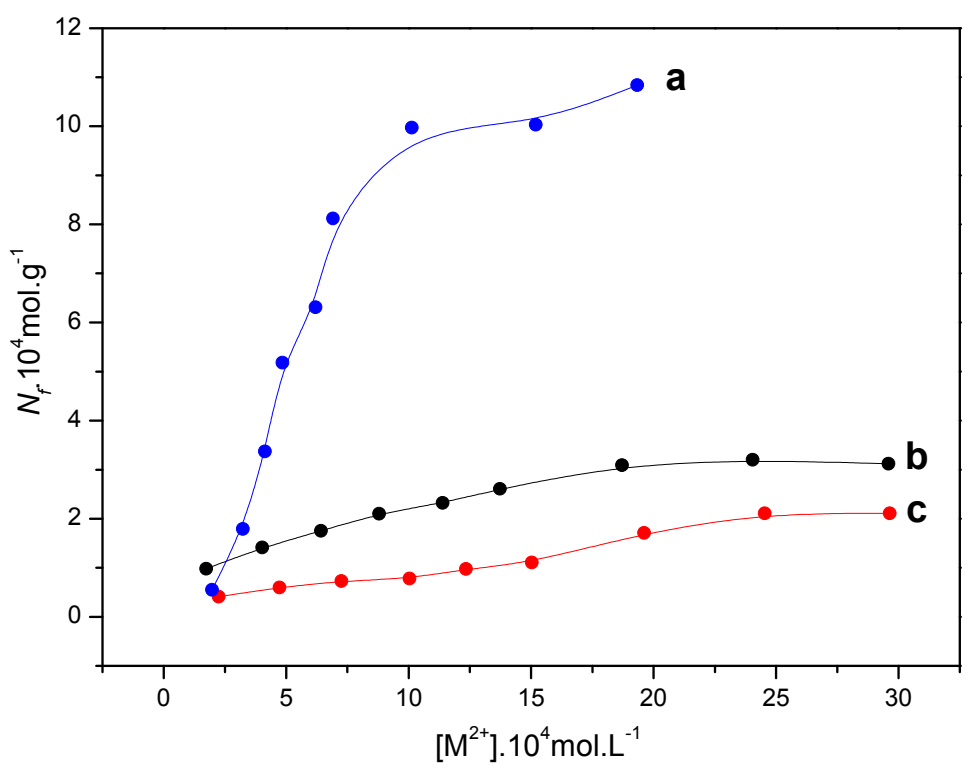

Figure 3. Adsorption isotherms of metal ions from aqueous medium on $\mathrm{SA}$ at $25 \pm 1{ }^{\circ} \mathrm{C}$ : a) $\mathrm{Cd}^{2+}$; b) $\mathrm{Cu}^{2+}$; $) \mathrm{Ni}^{2+}$

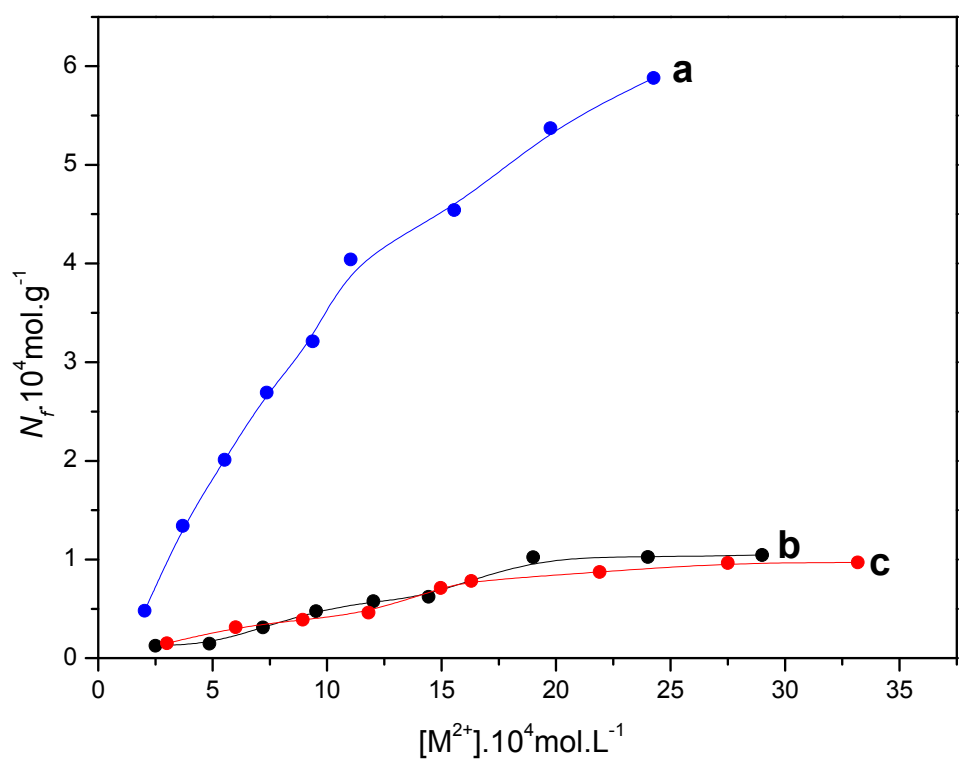

Figure 4. Adsorption isotherms of metal ions from ethanol $42 \%$ medium on SA at $25 \pm 1{ }^{\circ} \mathrm{C}:$ a) $\mathrm{Cd}^{2+}$; b) $\mathrm{Cu}^{2+}$; c) $\mathrm{Ni}^{2+}$ 


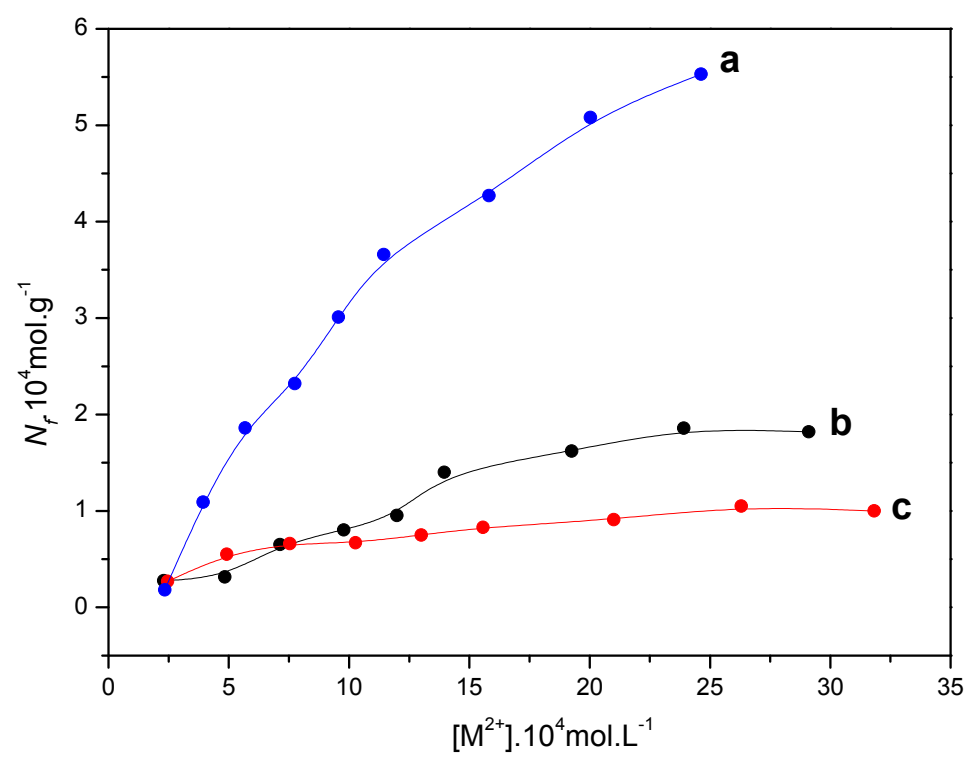

Figure 5. Adsorption isotherms of metal ions from ethanol $99 \%$ medium on $\mathrm{SA}$ at $25 \pm 1{ }^{\circ} \mathrm{C}$ : a) $\mathrm{Cd}^{2+}$; b) $\mathrm{Cu}^{2+}$; c) $\mathrm{Ni}^{2+}$

For $\mathrm{Cu}^{2+}$ ions, the values of $N_{f}$ were: aqueous solution $\left(3.09 \times 10^{-4} \mathrm{~mol} \mathrm{~g}^{-1}\right)$, ethanol $42 \%\left(1.03 \times 10^{-4} \mathrm{~mol} \mathrm{~g}^{-1}\right)$ and ethanol $99 \%\left(1.86 \times 10^{-4} \mathrm{~mol} \mathrm{~g}^{-1}\right)$, with $\mathrm{Cu}^{2+}$ ions concentrations ranging from 1.74 to $29.64 \mathrm{~mol} \mathrm{~L}^{-1}$. The values obtained for the $\mathrm{Ni}^{2+}$ ions were: aqueous solution $\left(2.11 \times 10^{-4} \mathrm{~mol} \mathrm{~g}^{-1}\right)$, ethanol $42 \%\left(0.97 \times 10^{-4} \mathrm{~mol} \mathrm{~g}^{-1}\right)$ and ethanol $99 \%\left(1.05 \times 10^{-4} \mathrm{~mol} \mathrm{~g}^{-1}\right)$, with $\mathrm{Ni}^{2+}$ ions concentrations ranging from 2.25 to $33.18 \mathrm{~mol} \mathrm{~L}^{-1}$. For the $\mathrm{Cd}^{2+}$ ions were not observed saturation of adsorption sites in the concentration range studied, not getting the maximum quantity of adsorbed metal $\left(N_{f}^{\max }\right)$. The adsorption properties decreased in the following sequence: $\mathrm{Cd}^{2+}>\mathrm{Cu}^{2+}>\mathrm{Ni}^{2+}$.

A schematic representation of equilibrium that occurs between the $\mathrm{SA}$ and $\mathrm{MX}_{2}$ is represented by Equation 1 .

$$
\mathrm{SA}_{(\mathrm{S})}+\mathrm{M}^{2+}+2 \mathrm{X}_{(\text {solvent })}^{-} \rightleftharpoons \operatorname{MSAX}_{2(\mathrm{~S})}
$$

Where $\mathrm{M}=$ metal ion $\left(\mathrm{Cu}^{2+}, \mathrm{Ni}^{2+}\right.$ and $\left.\mathrm{Cd}^{2+}\right)$ and $\mathrm{X}=$ chloride $\left(\mathrm{Cl}^{-}\right)$.

Based on the results, the SA presented an excellent potential for adsorption of the metal ions studied in different media. Similar results using materials analogs to SA been reported in the literature (Do Carmo \& Paim, 2012; Lessi et al., 1996; Salles et al., 2004).

More information about the system behavior can be obtained from a fit of the data to the modified Langmuir equation represented by Equation 2, from which one can obtain the linearization curve (Adamson, 1990; Langmuir, 1918).

$$
\frac{C_{s}}{N_{f}}=\frac{C_{s}}{N_{s}}+\frac{1}{N_{s} k}
$$

In this equation, $C_{s}$ is the concentration of the solution at equilibrium $\left(\mathrm{mol} \mathrm{L}^{-1}\right), N_{f}$ the quantity of solute adsorbed by the material $\left(\mathrm{g} \mathrm{mol}^{-1}\right), N_{s}$ is the adsorption capacity $\left(\mathrm{g} \mathrm{mol}^{-1}\right)$ and $k$ is the equilibrium constant. Plotting $C_{s} / N_{f}$ against $C_{s}$ obtains parameters that make possible to calculate the values of $k$ and $N_{s}$.

Figures 5, 6 and 7 represent the linearized Langmuir isotherms for the SA in the solvents studied for $\mathrm{Cu}^{2+}, \mathrm{Ni}^{2+}$ and $\mathrm{Cd}^{2+}$ ion, respectively. 


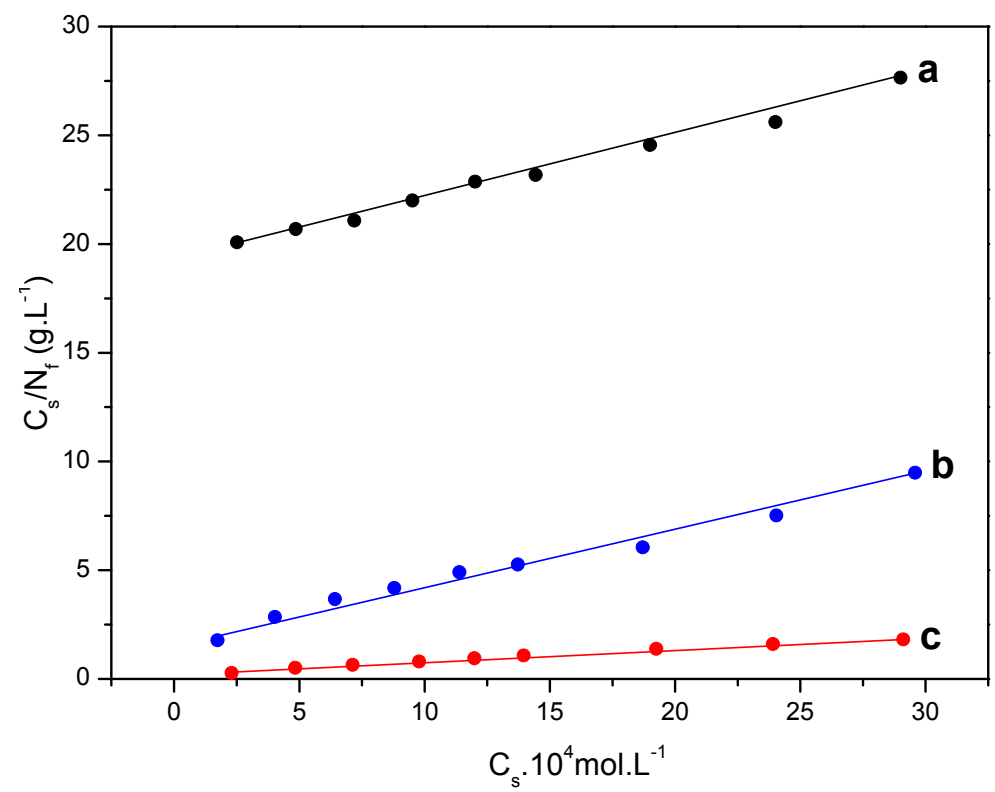

Figure 6. Adsorption isotherms of $\mathrm{Cu}^{2+}$ ions in several solvents solutions on SA as plot of $C_{s} / N_{f}$ against $C_{s}$ at $25 \pm$ $1{ }^{\circ} \mathrm{C}$ : a) ethanol $42 \%$; b) aqueous and c) ethanol $99 \%$

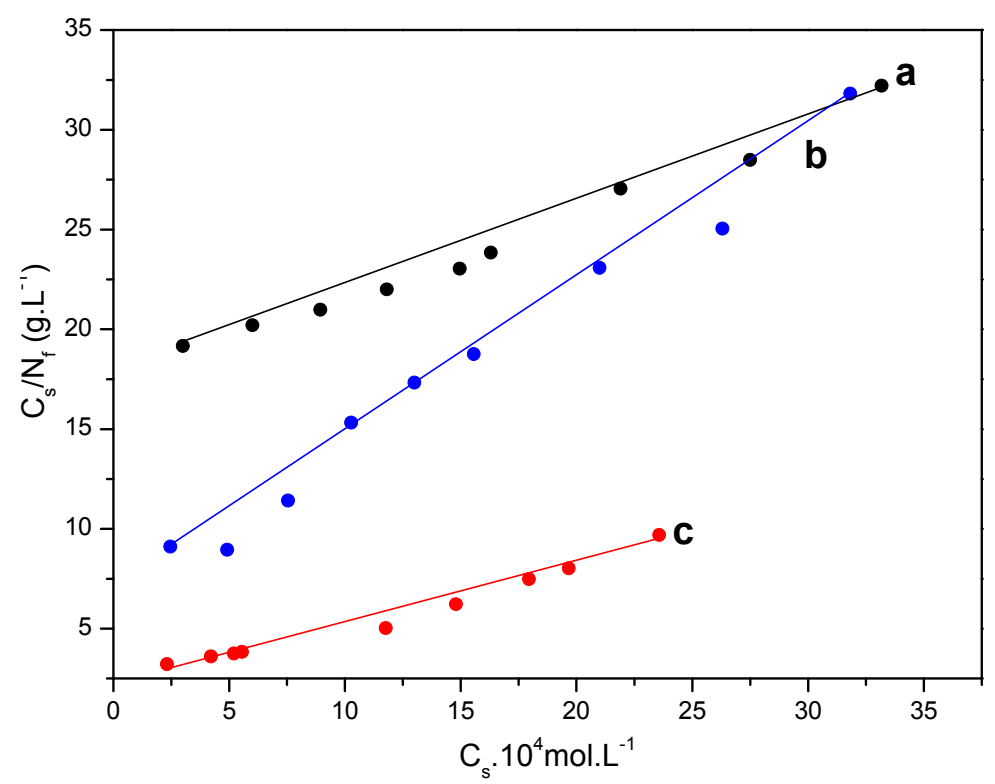

Figure 7. Adsorption isotherms of $\mathrm{Ni}^{2+}$ ions in several solvents solutions on $\mathrm{SA}$ as plot of $C_{s} / N_{f}$ against $C_{s}$ at $25 \pm$ $1{ }^{\circ} \mathrm{C}$ : a) ethanol $42 \%$; b) ethanol $99 \%$ and c) aqueous 


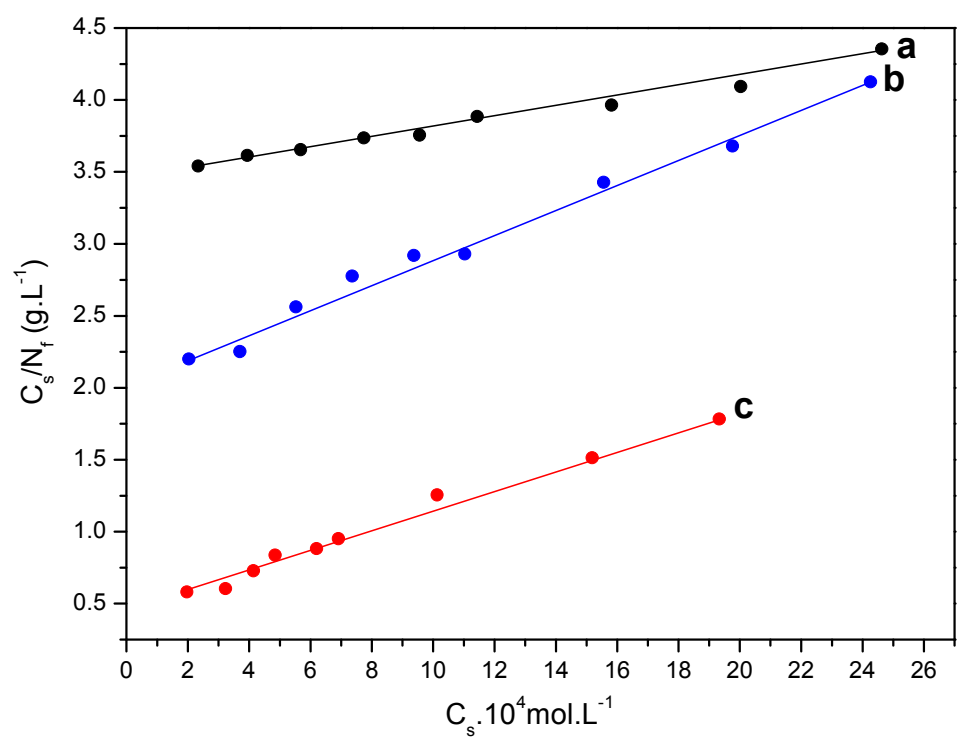

Figure 8. Adsorption isotherms of $\mathrm{Cd}^{2+}$ ions in several solvents solutions on SA as plot of $C_{s} / N_{f}$ against $C_{s}$ at $25 \pm$ $1{ }^{\circ} \mathrm{C}$ : a) ethanol $99 \%$; b) ethanol $42 \%$ and c) aqueous

Table 1. Adsorption of metal ions by SA from different solvents at $25 \pm 1{ }^{\circ} \mathrm{C}$ and the corresponding correlation coefficients (r)

\begin{tabular}{|c|c|c|c|c|c|}
\hline $\begin{array}{c}\text { Metal } \\
\text { Adsorbed }\end{array}$ & Solvent & $\begin{array}{c}N_{f}^{\max } 10^{4} \\
\left(\mathrm{~mol} \mathrm{~g}^{-1}\right)\end{array}$ & $\begin{array}{c}N_{s} 10^{4} \\
\left(\mathrm{~mol} \mathrm{~g}^{-1}\right)\end{array}$ & $\begin{array}{c}k 1^{3} \\
\left(\mathrm{~L} \mathrm{~mol}^{-1}\right)\end{array}$ & $\mathbf{r}$ \\
\hline \multirow{3}{*}{$\mathrm{CuCl}_{2}$} & Aqueous & 3.20 & 4.14 & 0.136 & 0.992 \\
\hline & Aqueous/Ethanol 42\% & 1.03 & 3.59 & 0.014 & 0.996 \\
\hline & Ethanol & 1.86 & 1.75 & 0.246 & 0.995 \\
\hline \multirow{3}{*}{$\mathrm{NiCl}_{2}$} & Aqueous & 2.11 & 3.36 & 0.136 & 0.989 \\
\hline & Aqueous /Ethanol 42\% & 0.97 & 2.34 & 0.025 & 0.993 \\
\hline & Ethanol & 1.05 & 1.29 & 0.119 & 0.991 \\
\hline \multirow{3}{*}{$\mathrm{CdCl}_{2}$} & Aqueous & 10.84 & 14.10 & 0.158 & 0.994 \\
\hline & Aqueous /Ethanol 42\% & 5.88 & 11.67 & 0.042 & 0.994 \\
\hline & Ethanol & 5.53 & 14.49 & 0.030 & 0.991 \\
\hline
\end{tabular}

Table 1 presents the data of adsorption in solution of $\mathrm{CuCl}_{2}, \mathrm{NiCl}_{2}$ and $\mathrm{CdCl}_{2}$ onto $\mathrm{SA}$ surface. The results show that there is a close proximity between the experimental values and empirical Langmuir isotherms. High values obtained for the equilibrium constant, in the order of magnitude of $10^{3} \mathrm{~L} \mathrm{~mol}^{-1}$, suggests that the complexes formed on the surface of the adsorbent are thermodynamically stable (Dias-Filho \& Do Carmo, 2006; Rosa et al., 2006).

\section{Conclusion}

Synthesis of octa-(3-chloropropyl)silsesquioxane (SS) and functionalization thereof with the ligand APTT were performed with success.

The composite obtained (SA), showed to be a power material to sorption of transition metals in several solvents. The excellent adsorptive capacity made possible the development of a method for determination of metal ions at trace level in real samples such as waste water, ethanol fuel and alcoholics beverages. 


\section{Acknowledgements}

Financial support for this research was supplied by Fundação de Amparo à Pesquisa do Estado de São Paulo (FAPESP-Processes: 2012/05438-1, 2003/12882-6 and 2012/11306-0) and Coordenação de Aperfeiçoamento de Pessoal de Nível Superior (CAPES).

\section{References}

Adamson, A. W. (1990). Physical Chemistry of Surfaces (5th ed.). New York, NY: John Wiley \& Sons.

Baney, R. H., Itoh, M., Sakakibara, A., \& Suzukit, T. (1995). Silsesquioxanes. Chem. Rev., 95, 1409-1430. http://dx.doi.org/10.1021/cr00037a012

Cai, S. L., Zheng, S. R., Fan, J., Tan, J. B., Xiao, T. T., \& Zhang, W. G. (2011). A series of 2D lanthanide (III) coordination polymers constructed from 2-(pyridin-3-yl)-1Himidazole-4,5-dicarboxylate. Journal of Solid State Chemistry, 184, 3172-3178. http://dx.doi.org/10.1016/j.jssc.2011.09.006

Chojnowski, J., Fortuniak, W., Rosciszewski, P., Werel, W., Łukasiak, J., Kamysz, W., \& Hałasa, R. (2006). Polysilsesquioxanes and oligosilsesquioxanes substituted by alkylammonium salts as antibacterial biocides. J. Inorg. Organomet. Polym. Mater., 16, 219-230. http://dx.doi.org/10.1007/s10904-006-9048-5

Chu, H., Yang, H., Huan, S., Lin, W., Shen, G., \& Yu, R. (2007). Adsorption of purpald SAMs on silver and gold electrodes: a Raman mapping study. Journal of Raman Spectroscopy, 38, 295-300. http://dx.doi.org/10.1002/jrs.1642

Cordes, D. B., Lickiss, P. D., \& Rataboul, F. (2010). Recent developments in the chemistry of cubic polyhedral oligosilsesquioxanes. Chem. Rev., 110(4), 2081-2173. http://dx.doi.org/10.1021/cr900201r

Dias-Filho, N. L., \& Do Carmo, D. R. (2006). Adsorption at silica, alumina, and related surfaces. In P. Somasundaran, Encyclopedia of Surface and Colloid Science (2nd ed.). New York, NY: Taylor \& Francis.

Dijkstra, T. W., Duchateau, R., Van Santen, R. A., Meetsma, A., \& Yap, G. P. A. (2002). Silsesquioxane Models for Geminal Silica Surface Silanol Sites. A Spectroscopic Investigation of Different Types of Silanols. $J$. Am. Chem. Soc., 124(33), 9856-9864. http://dx.doi.org/10.1021/ja0122243

Do Carmo, D. R., Dias-Filho, N. L., \& Stradiotto, N. R. (2007). Encapsulation of titanium (IV) silsesquioxane into the $\mathrm{NH}_{4} \mathrm{USY}$ zeolite: Preparation, characterization and application. Mater. Res. Bull., 42, 1811-1822. http://dx.doi.org/10.1016/j.materresbull.2006.12.001

Do Carmo, D. R., \& Paim, L. L. (2012). Investigation about the Copper Adsorption on the Chloropropylsilica Gel Surface Modified with a Nanoestructured Dendrimer DAB-Am-16: an Analytical Application for Determination of Copper in Different Samples. Mat. Res., 15(6), 1-9. http://dx.doi.org/10.1590/S1516-14392012005000163

Do Carmo, D. R., Paim, L. L., Dias-Filho, N. L., \& Stradiotto, N. R. (2007). Preparation, characterization and application of a nanostructured composite: Octakis(cyanopropyldimethylsiloxy)octasilsesquioxane. Appl. Surf. Sci., 253, 3683-3689. http://dx.doi.org/10.1016/j.apsusc.2006.07.080

Duchateau, R., Gerritsen, G., Van Santen, R. A., \& Yap, G. P. (2003). Boron, Aluminum, and Gallium Silsesquioxane Compounds, Homogeneous Models for Group 13 Element-Containing Silicates and Zeolites. Organometallics, 22(1), 100-110. http://dx.doi.org/10.1021/om0200858

Feher, F. J., \& Budzichowski, T. A. (1995). Silsesquioxanes as ligands in inorganic and organometallic chemistry. Polyhedron, 14(22), 3239-3253. http://dx.doi.org/10.1016/0277-5387(95)85009-0

Gnanasekaran, D., Madhavan, K., \& Reddy, B. S. R. (2009). Developments of Polyhedral Oligomeric Silsesquioxanes (POSS), POSS nanocomposites and their applications: A review. J. Sci. Ind. Res., 68, 437-464.

Handke, M., \& Kowalewska, A. (2011). Siloxane and silsesquioxane molecules-precursors for silicate materials. Spectroc. Acta Pt A-Molec. Biomolec. Spectr., 79, 749-757. http://dx.doi.org/ 10.1016/j.saa.2010.08.049

Hu, L., \& Shea, K. J. (2011). Organo-silica hybrid functional nanomaterials: how do organic bridging groups and silsesquioxane moieties work hand-in-hand? Chem. Soc. Rev., 40, 688-695. http://dx.doi.org/10.1039/c0cs00219d

Kuo, S. W., \& Chang, F. C. (2011). POSS related polymer nanocomposites. Prog. Polym. Sci., 36, 1649-1696. http://dx.doi.org/10.1016/j.progpolymsci.2011.05.002

Laine, R. M., \& Roll, M. F. (2011). Polyhedral phenylsilsesquioxanes. Macromolecules, 44, 1073-1109. 
http://dx.doi.org/10.1021/ma102360t

Langmuir, I. (1918). The adsorption of gases on plane surfaces of glass, mica and platinum. J. Am. Chem. Soc., 40(9), 1361-1403. http://dx.doi.org/10.1021/ja02242a004

Lessi, P., Dias-Filho, N. L., Moreira, J. C., \& Campos, J. T. S. (1996). Sorption and preconcentration of metal ions on silica gel modified with 2,5-dimercapto-1,3,4-thiadiazole. Anal. Chim. Acta, 327, 183-190. http://dx.doi.org/10.1016/0003-2670(96)00074-8

Li, G., Wang, L., Ni, H., \& Pittman Jr., C. U. (2001). Polyhedral oligomeric silsesquioxane (POSS) polymers and copolymers: a review. J. Inor.g Organomet., P11, 123-154. http://dx.doi.org/1053-0495/01/0900-0123/0

Lorenz, V., Fischer, A., \& Edelmann, F. T. (2000). Silsesquioxane chemistry, 6 The first beryllium silsesquioxane: synthesis and structure of $\left[\mathrm{Cy}_{7} \mathrm{Si}_{7} \mathrm{O}_{12} \mathrm{BeLi}\right]_{2} \cdot 2 \mathrm{THF}$. Inorg. Chem. Comm., 3(6), 292-295. http://dx.doi.org/10.1016/S1387-7003(00)00071-X

Paim, L. L. (2007). Preparação, caracterização e aplicação de materiais nanoestruturados suportados em sílica gel. Dissertação (Mestrado). Faculdade de Engenharia, Universidade Estadual Paulista "Júlio de Mesquita Filho", Ilha Solteira-SP.

Provatas, A., Luft, M., Mu, J. C., White, A. H., Matisons, J. G., \& Skelton, B. W. (1998). Silsesquioxanes: Part I: A key intermediate in the building of molecular composite materials. J. Organomet. Chem., 565, 159-164. http://dx.doi.org/ 10.1016/S0022-328X(98)00450-1

Rosa, A. H., Goveia, D., Bellin, I. C., Da Silva, L. S., Dias-Filho, N. L., \& De Magalhães, P. P. (2006). New analytical procedure based on a cellulose bag and ionic exchanger with p-aminobenzoic acid groups for differentiation of labile and inert metal species in aquatic systems. Anal Bioanal Chem, 386, 2153-2160. http://dx.doi.org/ 10.1007/s00216-006-0847-x

Salles, J. A. A., Faria, F. P., Prado, A. G. S., \& Airoldi, C. (2004). Attachment of 2-aminomethylpyridine molecule onto grafted silica gel surface and its ability in chelanting cations. Polyhedron, 23(5), 719-725. http://dx.doi.org/10.1016/j.poly.2003.11.051

Silverstein, R. M., \& Welbster, F. X. (2005). Spectrometric identification of organic compounds (7th ed.). New York, NY: John Wiley \& Sons.

Tanaka, K., \& Chujo, Y. (2012). Advanced functional materials based on polyhedral oligomeric silsesquioxane (POSS). J. Mater. Chem., 22, 1733-1746. http://dx.doi.org/10.1039/c1jm14231c

Xu, D., Loo, L. S., \& Wang, K. (2011). Characterization and Diffusion behavior of chitosan POSS composite membranes. J. Appl. Polym. Sci., 122, 427-435. http://dx.doi.org/10.1002/app.34146

Yin, P., Tian, Y., Wang, Z., Qu, R., Liu, X., Xu, Q., \& Tang, Q. (2011a). Synthesis of functionalized silica gel with poly(diethylenetriamine bis(methylene phosphonic acid)) and its adsorption properties of transition metal ions. Mater. Chem. Phys., 129, 168-175. http://dx.doi.org/10.1016/j.matchemphys.2011.03.067

Yin, P., Wang, C., Yang, Y., Tian, Y., \& Yu, Z. (2011b). Thermodynamics and kinetics of Au(III) adsorption on silica gel chemically modified by diethylenetriamine bis(methylene phosphonic acid). J. Chem. Eng. Data, 56, 450-457. http://dx.doi.org/10.1021/je100817k 